\title{
Power factor improvement for a three-phase system using reactive power compensation
}

\author{
Majid Ali ${ }^{1}$, Faizan Rashid ${ }^{2}$, Saim Rasheed ${ }^{3}$ \\ 1,2 Department of Electrical Engineering, The University of Lahore, Lahore, Pakistan \\ ${ }^{3}$ Department of Information Technology, King Abdulaziz University, Jeddah, Saudi Arabia
}

\section{Article Info \\ Article history: \\ Received Apr 10, 2021 \\ Revised Sep 7, 2021 \\ Accepted Sep 29, 2021}

\section{Keywords:}

APFC

Capacitor bank

Complex power

Current transformer

Potential transformer

Power factor

\begin{abstract}
For all industrial and distribution sites, the lagging power factor of electrical loads is a common problem. In the early days, it was corrected manually by adding the capacitor banks of certain values in parallel. Automatic power factor correction (APFC) using a capacitor bank helps to make a power factor that is close to unity. It consists of a microcontroller that processes the value of the power factor to enable the system and monitor the power factor if it falls below (0.77) from the specified level. This paper presents the automatic correction of the power factor by adding the capacitors banks automatically of the desired value in a three-phase system in the form of binary coding (0-7). The main purpose of this system is to maintain the power factor as close as to unity, for the experimental case, it is set to $(0.93)$ which helps to decreases the losses and ultimately increase the efficiency of the system.
\end{abstract}

This is an open access article under the CC BY-SA license.

\section{Corresponding Author:}

Majid Ali

Department of Electrical Engineering

The University of Lahore

1-km Defence road of raiwind road Lahore, 54000, Pakistan

Email: engr.majidali.baig@gmail.com

\section{INTRODUCTION}

Power factor (PF) is defined as the cosine of angle between the voltage and current. Most of the loads have low PF due to inductive nature in them. And due to low PF the current of the system increases. To reduce the current, this PF should be as close to as unity. The analysis of power factor can be made by drawing power triangle as shown in Figure 1. Due to this low PF the equipment will require larger no of rating, copper losses, conductor size and would result in poor handling capacity of the system. The PF of the system can be improved by adding the capacitor in parallel with the load, since it will provide the leading current $I_{C}$ which neutralizes the lagging current I drawn by the system as shown in the Figure 2 . The resultant current I' have the less magnitude as compared to I.

Other's methods to improve the PF are using phase advancers and synchronous condensers. The capacitor current $I_{c}$ cancels the lagging reactive component of load current. Capacitance of capacitor to improve PF from $\cos \theta_{1}$ and $\cos \theta_{2}$.

$$
X_{c}=\frac{V}{I_{c}}=\frac{1}{\omega C}
$$

An automatic power factor control method proposed for the both inductive and resistive loads [1]. Power quality is a big issue these days due to an increase in the inductive loads. Power quality can be 
improved by appropriately monitoring the load PF. Whenever the load power factor decreases than the certain value, line current increases which ultimately leads to a higher voltage drop and line losses.

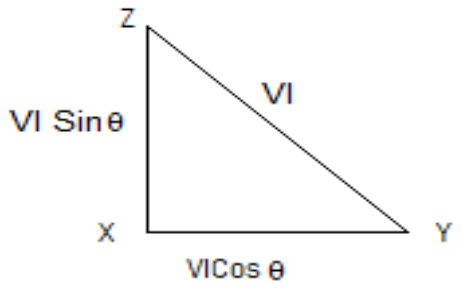

Figure 1. Power triangle

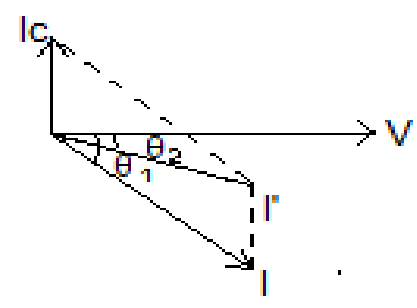

Figure 2. Phasor representation of currents

Where,

$\mathrm{XY}=\mathrm{VI} \operatorname{Cos} \theta$, the active power in kilo Watts

$\mathrm{XZ}=\mathrm{VI} \operatorname{Sin} \theta$, the reactive power in kilo VAR

$\mathrm{YZ}=\mathrm{VI}$, the apparent power in kilo VA

An automatic power factor control method presented Microcontroller based capacitor bank switching [2]. If the value of the PF goes below the predetermined value of PF, specified value of the capacitance will be required to achieve the desired value using (1) [3]. The phase difference generated due to the low PF is proportional to the signal strength of the pulse width. A Microcontroller is being used to monitor the power factor and it is automatically switch on the capacitors of the required capacity [4]. A comparative analysis using the solid state relay to improve the PF is used in [5] which uses a relay to detect the value of the power factor and compares it with a pre-set value. After the comparison, if the pre-set value comes out to be less the calculated value, then the capacitor is automatically added, by this design [6] Various methods for reactive power compensation are proposed such as series compensation, shunt compensation, static VAR commutator, STATCOM, and synchronous condenser.

Industrial usage of inductive loads is the biggest cause of power loss and power factor lagging [7]. That technique can be used in industries, power systems, and households and it is adding capacitance according to the demand or requirement. In that technique, the power factor was improved from 0.66 to 0.92 value. An automatic power factor compensation (APFC) technique is used for the medical industries in Malaysia and the power factor improved from 0.85 to 0.90 [8]. The APFC contributes to low power loss and more cost-efficient. The APFC technique is beneficial is coping with the challenge of limited energy resources that may arise under the situation, when there is high power demand. An automatic power factor correction using Arduino uno technique is used to improve the power factor by using OR Gates [9].

An automatic power factor metering using Arduino is used in, power systems, and households and it is adding capacitance according to the demand or requirement [10]. In that technique, the power factor was improved from 0.68 to 0.90 value. Automatic power factor correction techniques along with energy monitoring system is proposed consist of a power supply that runs at $230 \mathrm{~V}$ at $50 \mathrm{~Hz}$ frequency and then to control the voltage use step down transformer and bridge rectifie [11]. Voltage sensors and current sensor circuits are used for the observation of these quantities. Microcontroller and liquid crystal display (LCD) are being used for monitoring and relay drivers are used for the implementation of commands [12]. There are various methods of power factor correction unit, one of the old methods of low power factor correction includes the installation of fixed capacitors for the compensation of active power [13].

Nowadays efficient methods of power distribution are becoming very important because of the demand for electricity in every sector (industrial, residential, commercial). In this scenario we learn about the technique of load sharing of transformer and improve power factor automatically [14]. As the power factor decreases, it causes electrical losses in a system which is due to increase in the size of conductor. For economical operation, a PF correction unit allows the device to restore its PF close to unity. Reduced power system losses, enhanced load carrying capacities, enhanced voltages for the benefits of power factor correction [15]. The foremost reason for this work is to develop an automatic power factor correction (APFC) system capable of tracking the power consumption of a system and enhancing its PF routinely.

In industry induction motors are used commonly due to the low cost and robustness and removes the penalty factor [16], [17]. For mining purposes, it acts as a prime mover. At no-load condition, the induction motor is a low power factor. Algorithms are designed to improve power factor for three-phase induction motors using programmable system on chip (PSoC3) [18]. A three-leg rectifier-inverter introduces which 
works as both boost converter and buck converter. A technique for enhancing the capacity of synchronous generators at the distant ends of rural distribution where the power factor was small and the line resistance was high. These methods have been proposed only for the inductive loads [19], [20]. If the power factor is lagging, the system starts consuming more power from utility and the extra power utility gives a penalty [21]. Our first and foremost priority of industries make power factor nearer to unity [22]. Ideally power factor must be near to unity it makes voltage stability, minimize power losses and also increase the power system efficiency [23], [24].

The earlier power factor was 0.65 before adding the reactive power in this paper, and the power factor has been enhanced to 0.93 . In order to achieve that, the capacitor of $22 \mathrm{uF}$ has been mounted. Conclusively, an enhanced power factor of 0.28 has been achieved. Another research on APFC technique has been carried out in the paper automatic power factor correction utilizing reactive power compensation for three phase systems [2].

In this paper the power factor has been improved by using the capacitors banks and by using microcontroller for three phase systems. Before the system automatic power factor correction utilizing reactive power compensation for three phase systems the conclusion was per year payment before corrected is $12.59 \$$ and per year payment after power factor corrected is $9.27 \$$ and annual savings is $3 \$$ [7]. After the design of systems the conclusion was per year payment before corrected is $13.12 \$$ and per year payment after power factor corrected is $9.12 \$$ and annual savings is $4 \$$. The annual savings is to increase in the design, so automatic power factor correction utilizing reactive power compensation is better than the previous design.

\section{BLOCK DIAGRAM OF SYSTEM}

Complete block diagram of the system is shown in Figure 3. Three phase supply is used (phase to neutral 230V). CT is connected to source in series to (A6). PT is connected to source parallel to (A8). Phase difference or zero crossing can be measured by voltage and current divider circuit. Microcontroller ATmega2560 is used to operate relay and relay operates capacitor banks which is connected in strings.

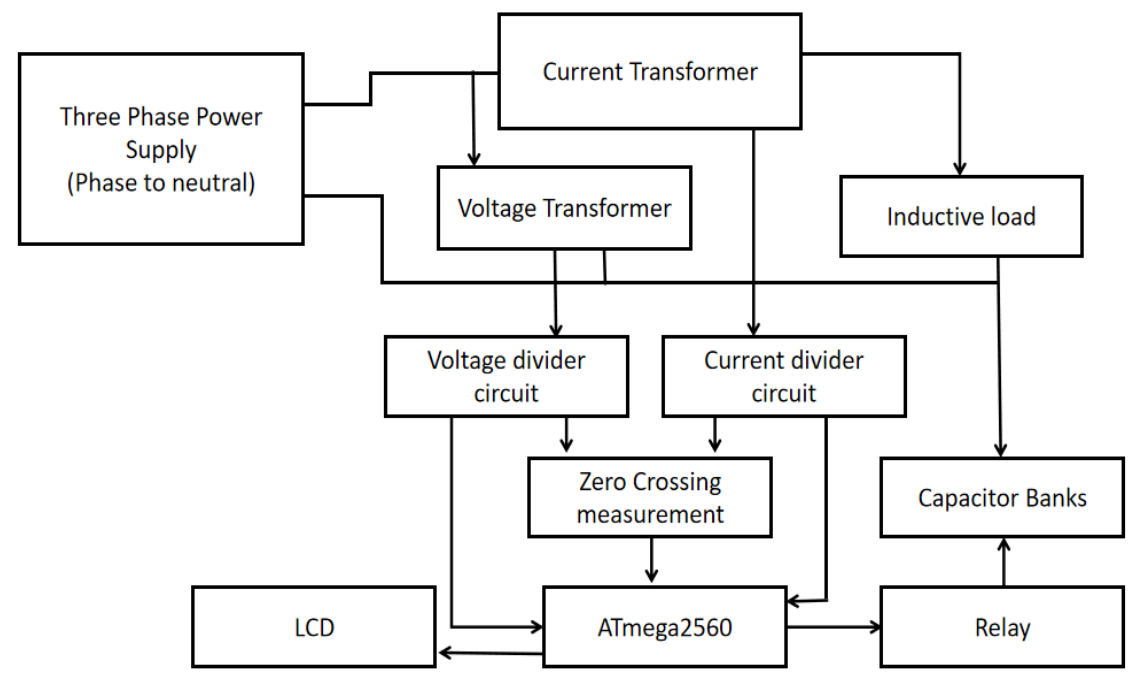

Figure 3. Block diagram

\section{SYSTEM FLOW CHART}

Step-1: Initially voltage and current signal is sensed as input signal by microcontroller (Arduino Mega2560). Step-2: Calculation and display of voltage, current, power factor and apparent power.

Step-3

$$
\mathrm{Q}=\sqrt{\mathrm{S}^{2}-\mathrm{P}^{2}}
$$

Step-4: Phase shift is measured between voltage and current signal.

Step-5: If $\mathrm{PF}>0.95$ applied Phase A inductive load is on. If $\mathrm{PF} \leq 0.95$ allied Phase A and Phase B inductive loads are on. If $\mathrm{PF}<0.95$ applied Phase A, B and C inductive load are on. Figure 4 parades the flow chart of the system.

Power factor improvement for a three-phase system using reactive power compensation (Majid Ali) 


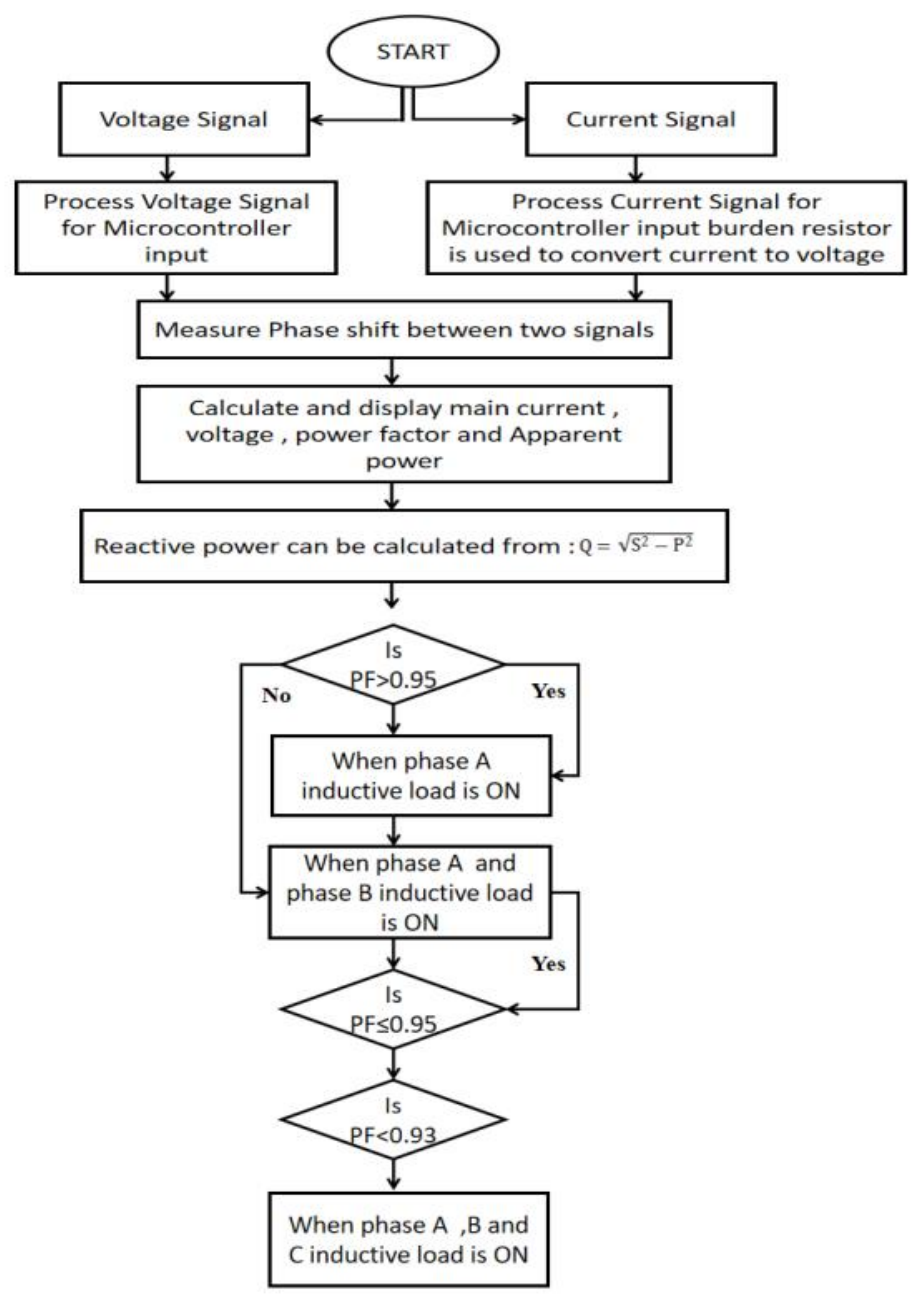

Figure 4. Flow chart

\section{RESULTS AND DISCUSSIONS}

\subsection{Simulation results}

Three phase supply is used and the power factor of each phase was improved. Each phase is connected with potential transformer (PT) and current transformer (CT). Voltages of each phase measured by PT and step down to $5 \mathrm{~V}$ through using potential divider for making appropriate voltages for microcontroller [25]. Similarly, Current is measured through CT. Each phase is connected with four capacitors bank string and these four capacitor bank strings are used to compensate reactive power. Each phase has 6 capacitors (When phase A, B and C inductive load is on) and total 18 capacitor are used for 3 -phase for minimizing the reactive power. Figure 5 show proteus simulation circuit. Results are displayed on LCD $20 \times 4$.

\subsubsection{Simulation calculation}

Proteous simulation results are shown in Table 1. When all three phases inductive loads are on, the number of capacitors is on 18 automatically and its binary number is (10010). At no load power factor is 0.78 and with load power factor is 0.93 (targeted value of PF) to improve the efficiency of three phase system. The load use in design is $41.82 \mathrm{KW}$.

Table 1. Software calculation results

\begin{tabular}{ccccccc}
\hline Sr. & Voltage (V) & Current (A) & Apparent power (KVA) & Reactive power (KVAR) & Capacitor ON & PF \\
\hline 1 & $139 \mathrm{~V}$ & $20.67 \mathrm{~A}$ & $54.31 \mathrm{KVA}$ & $34.65 \mathrm{VAR}$ & 00 & 0.78 \\
2 & $220 \mathrm{~V}$ & $8.91 \mathrm{~A}$ & $44.96 \mathrm{KVA}$ & $667 \mathrm{VAR}$ & 18 & 0.93 \\
\hline
\end{tabular}




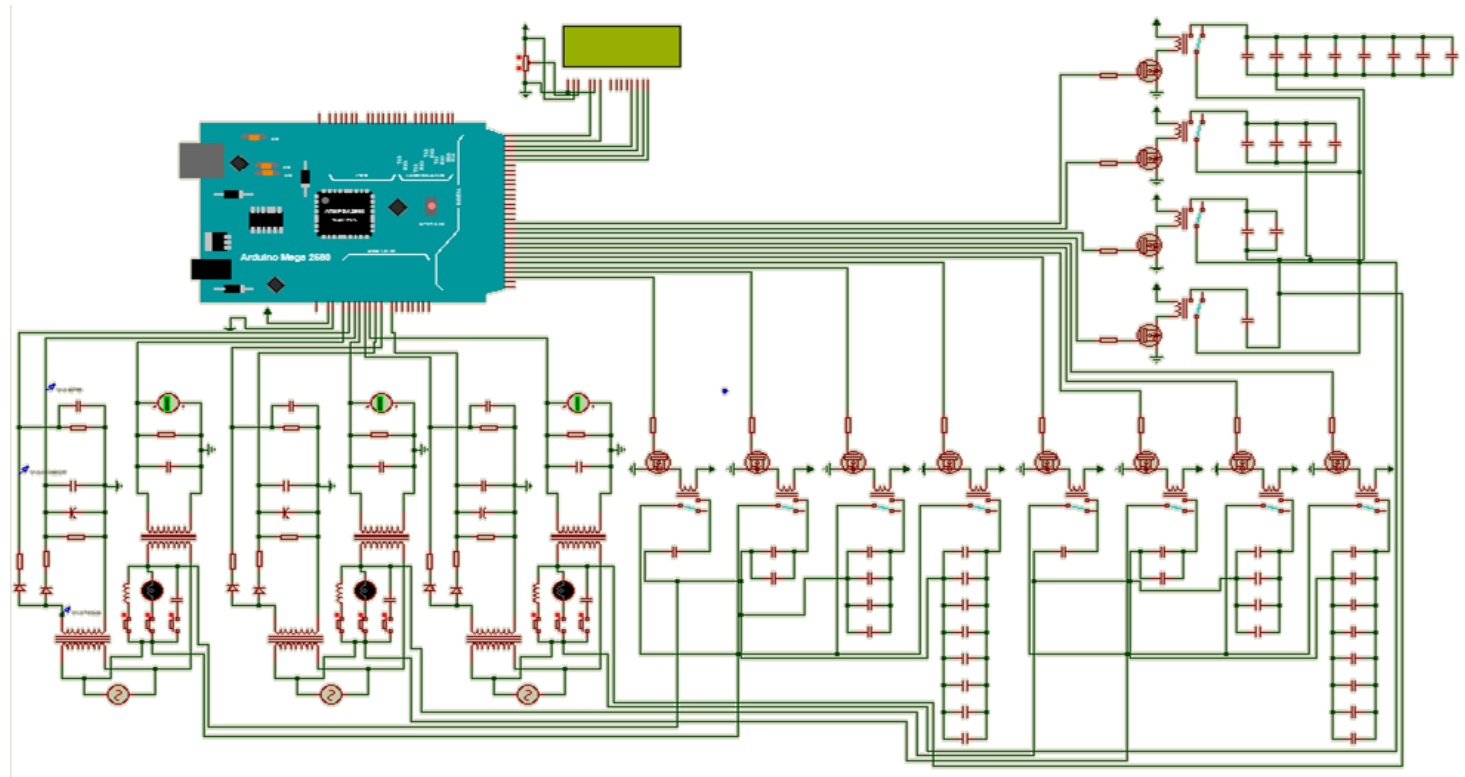

Figure 5. Proteous simulation

\subsubsection{Simulation LCD display results $20 \times 4$}

LCD $20 \times 4$ display the results of low value of power factor (0.78) and improve value of power factor (0.93). Switching of capacitor are done automatically and hence we improve the power factor. Figure 6 shows the low and improve power factor results.

\begin{tabular}{|c|c|}
\hline LCD & $\begin{array}{ll}L C D \\
\text { LWOAL }\end{array}$ \\
\hline$U=139 \quad A=20.67$ & $\mathrm{~A}=08.91$ \\
\hline $\begin{array}{l}\mathrm{PF}=0.78 \quad \mathrm{C}=60 \\
\text { Power Factor is Low }\end{array}$ & $\begin{array}{l}\mathrm{PF}=0.93 \quad \mathrm{C}=18 \\
\text { Power } \mathrm{F} \text { actor improve }\end{array}$ \\
\hline $28 \% 2 \frac{16}{3} 85883885$ & 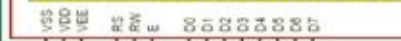 \\
\hline
\end{tabular}

Figure 6. Simulation results LCD display

\subsubsection{Voltage divider circuit}

Step down transformer is used to step down voltages up to $16.148 \mathrm{~V}$ and then potential divider is used to step down further voltages. After designing the circuit and voltages are step down up to $2.34 \mathrm{~V}$. Design of potential divider is given in Figure 7.

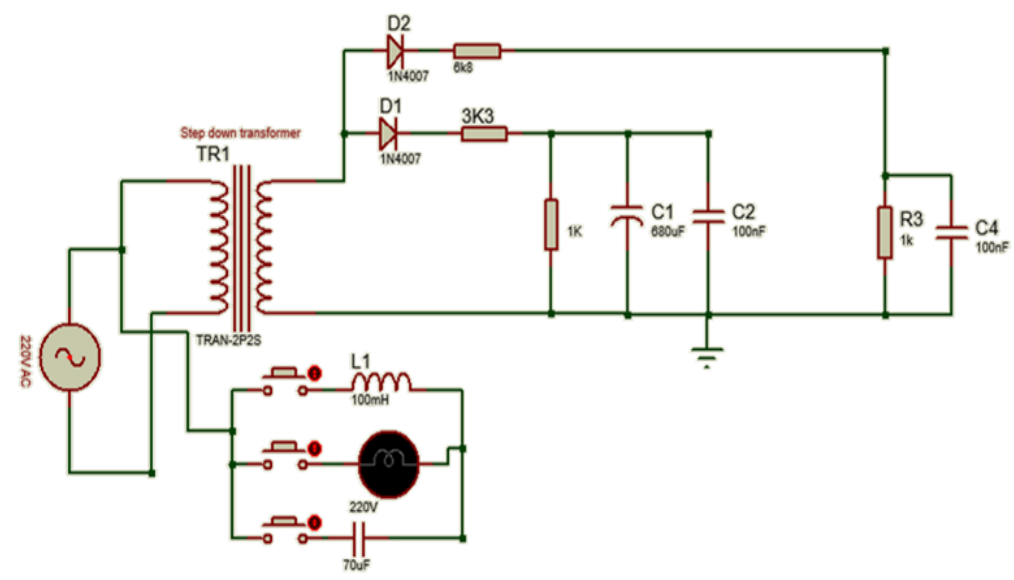

Figure 7. Voltage divider circuit 
Calculation of the voltage division is calculated as;

$\mathrm{V}_{\text {acrossarduino }}=\frac{V_{\text {across PTonSecondaryside }} \times R 2}{R 1+R 2}$

$V_{\text {acrossPTonSecondaryside }=16,1487}$

$R_{1=} 3.3 k, R_{2}=1 k$

Putting values in (3)

$V_{\text {acrossarduino }}=\frac{(16.1487 \times 1) K}{(1+3.3) K}$

$V_{\text {acrossarduino }}=3.75 \mathrm{~V}\left(\mathrm{ADC} 767\right.$ number Arduino pin $\left.A_{1}\right)$

\subsubsection{Current divider circuit}

CT is connected to the source in series to measure the current. Further current division circuit is used to convert current into voltages because Arduino Mega2560 detect voltages in terms of binary coding. Design of current divider is given in Figure 8.

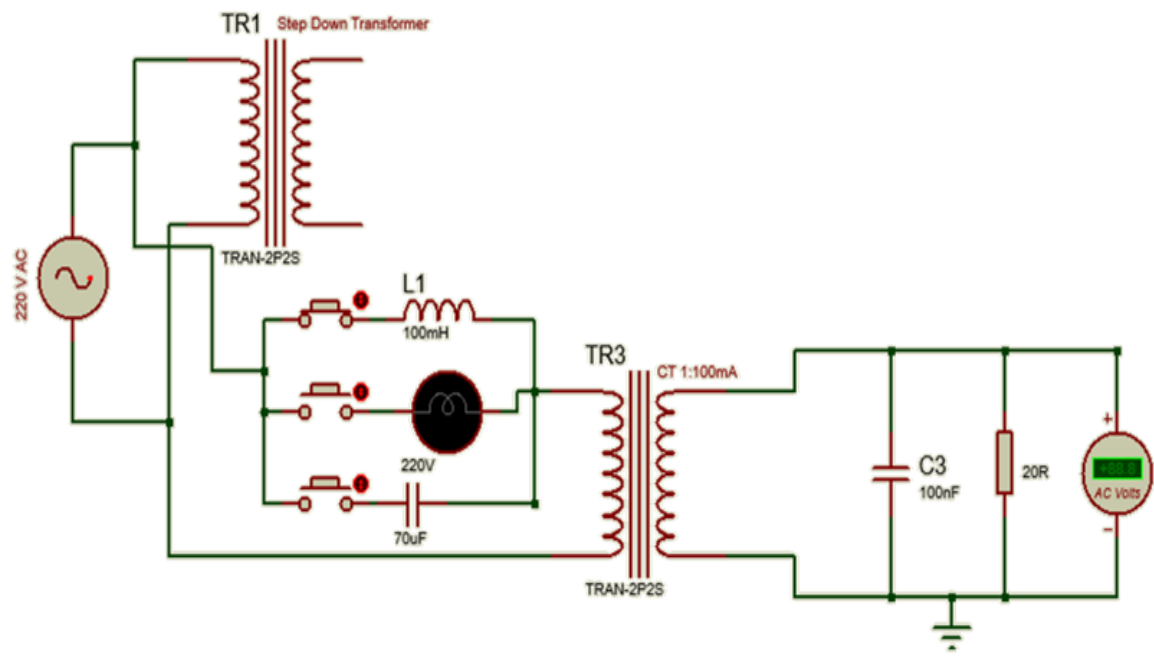

Figure 8. Current divider circuit

Calculation of Current Divider circuit is as follows;

$$
\mathrm{V}=\mathrm{IR}
$$

Putt values in (5)

$\mathrm{V}=(100 \mathrm{~mA})(25 \mathrm{ohm})$

$\mathrm{V}=2.5 \mathrm{~V}$ (ADC number is 511) in Arduino pin $A_{0}$,

\subsubsection{Capacitor calculations}

For the designing of the circuit of capacitors, active, reactive and apparent power is calculated. All these powers of each phases are calculated separately. After performing all these calculations capacitors of $22 \mu \mathrm{F}$ is selected design of capacitance circuit is given in Figure 9.

Calculation for capacitors is as;

$\mathrm{S}_{\text {old }}=\frac{\mathrm{P}}{\mathrm{PF}}=\frac{41.82}{0.65}$

$\mathrm{S}_{\text {old }}=64.33 \mathrm{KVA}$ 


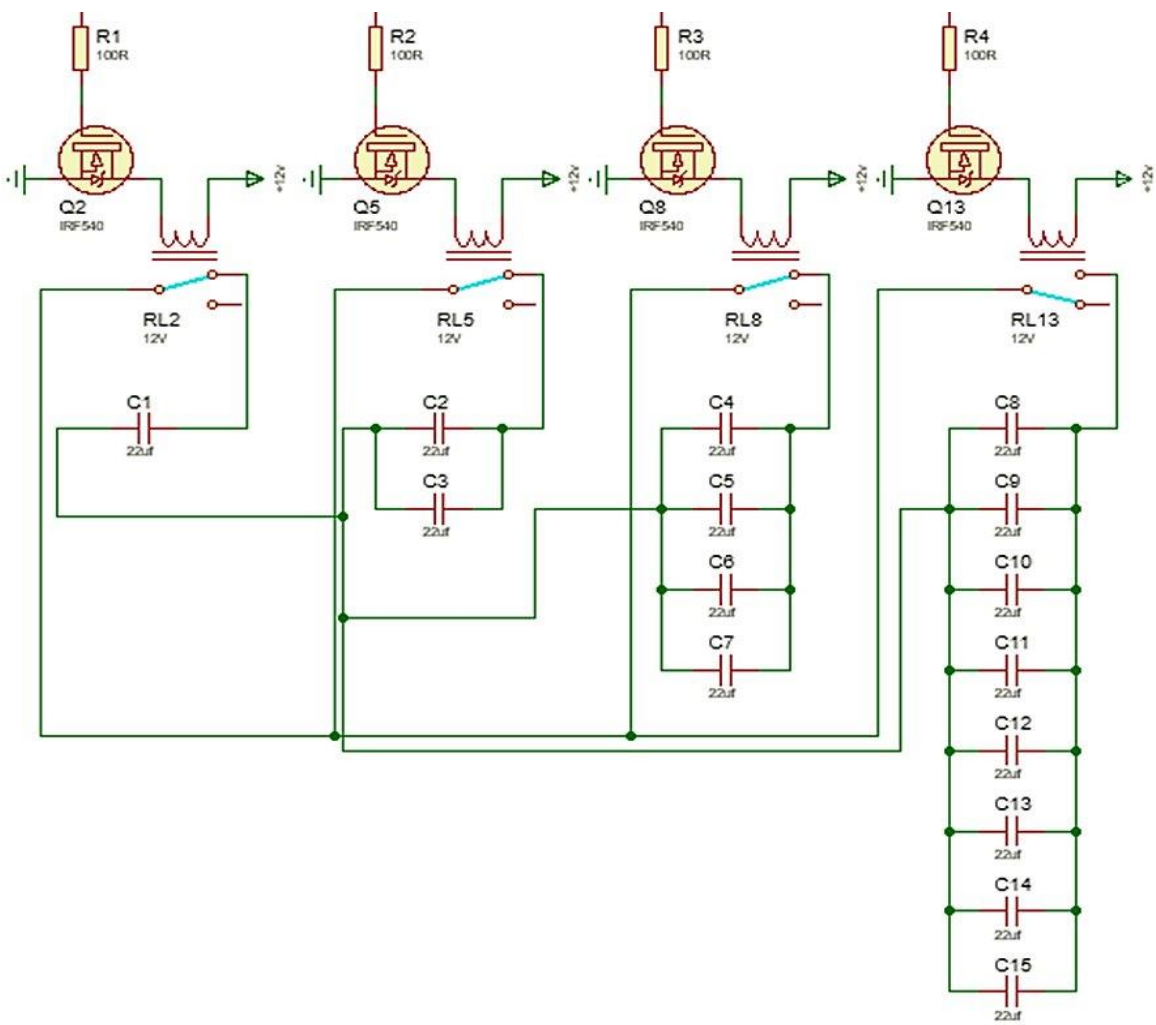

Figure 9. Capacitance circuit

The reactive power is calculated as;

$$
\mathrm{Q}_{\mathrm{old}}=\sqrt{\mathrm{S}^{2}-\mathrm{P}^{2}}
$$

Putting values in (7)

$$
\begin{aligned}
& \mathrm{Q}_{\text {old }}=\sqrt{64.33^{2}-41.82^{2}} \\
& \mathrm{Q}_{\text {old }}=48.88 \mathrm{KVAR} \\
& \mathrm{S}_{\text {new }}=\frac{\mathrm{P}}{\mathrm{PF}}=\frac{41.82}{0.93} \\
& \mathrm{~S}_{\text {new }}=44.96 \mathrm{KVA} \\
& \mathrm{Q}_{\text {new }}=\sqrt{\mathrm{S}^{2}-\mathrm{P}^{2}}
\end{aligned}
$$

Putting values in (9)

$$
\begin{aligned}
& Q_{\text {new }}=\sqrt{44.96^{2}-41.82^{2}} \\
& Q_{\text {new }}=54.31 \mathrm{KVAR} \\
& Q_{\text {required }}=Q_{\text {old }}-Q_{\text {new }}
\end{aligned}
$$

Putting values $Q_{\text {old }}$ and $Q_{\text {new }}$ in (12)

$\mathrm{Q}_{\text {required }}=48.88-16.507$

$\mathrm{Q}_{\text {required }}=32.373 \mathrm{KVAR}$

Reactive power required of each phase; 
$\mathrm{Q}=\frac{32.373}{3}$

$\mathrm{Q}=10.79 \mathrm{~A}$

Total current before capacitor added;

$\mathrm{S}_{\text {new }}=\mathrm{V}_{\mathrm{rms}} \times \mathrm{I}_{\mathrm{rms}}$

Re-arrange (14)

$$
\mathrm{I}_{\mathrm{rms}}=\frac{\mathrm{S}_{\mathrm{new}}}{\mathrm{V}_{\mathrm{rms}}}
$$

Putting values in (15)

$\mathrm{I}_{\mathrm{rms}}=\frac{44.96}{221}=203 \mathrm{~A}$

Active Component of current $=\mathrm{I}_{\text {active }}=\mathrm{I}_{\mathrm{rms}} \cos \emptyset$

$\mathrm{I}_{\text {active }}=203 \times 0.65=131.95 \mathrm{~A}$

Reactive component of current

$\mathrm{I}_{\text {old reactive }}=\mathrm{I}_{\text {rms }} \sin \emptyset$

$\emptyset=\cos ^{-1} 0.65=49.45$

$\sin 49.45=0.7598$

$\mathrm{I}_{\text {old reactive }}=\mathrm{I}_{\text {rms }} \sin \emptyset$

Putting values in (19)

$=203 \times 0.7598=154 \mathrm{~A}$

New reactive component is;

$\mathrm{I}_{\text {new reactive }}=\mathrm{I}_{\mathrm{rms}} \sin \emptyset$

Putting values in $(20)$

$I_{\text {new reactive }}=203 \times \sin 21.56=74.59 A$

The capacitive value of current is calculated by the difference in old reactive current and new reactive current component and capacitor is added in star sequence.

$$
\begin{aligned}
& \mathrm{I}_{\mathrm{c}}=\mathrm{I}_{\text {old reactive }}-\mathrm{I}_{\text {new reactive }} \\
& \mathrm{I}_{\mathrm{c}}=154-74.59=79.41 \mathrm{~A} \\
& \mathrm{C}=\frac{\mathrm{I}_{\mathrm{c}}}{2 \times 3.14 \times \mathrm{f} \times \mathrm{V}_{\mathrm{ph}}}
\end{aligned}
$$

Putting values in 22

$$
\begin{aligned}
& \mathrm{C}=\frac{79.41}{2 \times 3.14 \times 50 \times 220 \times \sqrt{3}} \\
& \mathrm{C}=66 \mathrm{uF} \\
& C=\frac{66 u F}{3}=22 u F
\end{aligned}
$$

Each capacitor value is $22 \mathrm{uF}$. 


\subsubsection{Per year cost before correction} $S_{\text {old }}=64.33 \mathrm{KVA}$

Per Month Payment $=0.017 \$ \times 64.33=1.0937 \$ /$ month

Per Year Payment $=1.0937 \$ \times 12=13.12 \$ /$ year

\subsubsection{Per year cost after correction}

$\mathrm{S}_{\text {new }}=44.96 \mathrm{KVA}$

Per Moth Payment $=0.017 \$ \times 44.96=0.76 \$ /$ month

Per Year Payment $=0.76 \$ 12=9.12 \$ /$ year

Saved dollar $(\$)=$ Per year payment before corrected-per year payment after corrected

Saved dollar $(\$)=13.12 \$-9.12 \$=4 \$$

The compiled data is shown in Table 2.

\begin{tabular}{cll} 
Table & 2. Savings after correction of power factor \\
\hline No & Status & Dollar $(\$)$ \\
\hline 1 & Per year payment before corrected & $13.12(\$)$ \\
2 & Per year payment after corrected & $9.12(\$)$ \\
3 & Saved dollar $(\$)$ & $4(\$)$ \\
\hline
\end{tabular}

\subsubsection{Simulation results low $P F$}

Figure 10 shows the waveform of low power factor (Phase A, Phase B and Phase C).In Phase A $V_{r m s}=212 V$, Peak Volage is $V_{p}=299 \mathrm{~V}$ and Peak Current is $I_{p}=8.71 \mathrm{~A}$ and average voltage is $V_{\text {avg }}=190 \mathrm{~V}$ and Rms value of current is $I_{r m s}=6.16$ A.In Phase $B V_{r m s}=213 V$, Peak Volage is $V_{p}=301 \mathrm{~V}$ and Peak Current is $I_{p}=8.69 A$ and average voltage is $V_{a v g}=191 \mathrm{~V}$ and $R m s$ value of current is $I_{r m s}=6.17 A$.In Phase $C$ and $R m s$ value of current is $I_{r m s}=6.17 A V_{r m s}=212 V$, Peak Volage is $V_{p}=300 \mathrm{~V}$ and Peak Current is $I_{p}=8.72 A$ and average voltage is $\mathrm{V}_{\text {avg }}=191 \mathrm{~V}$.

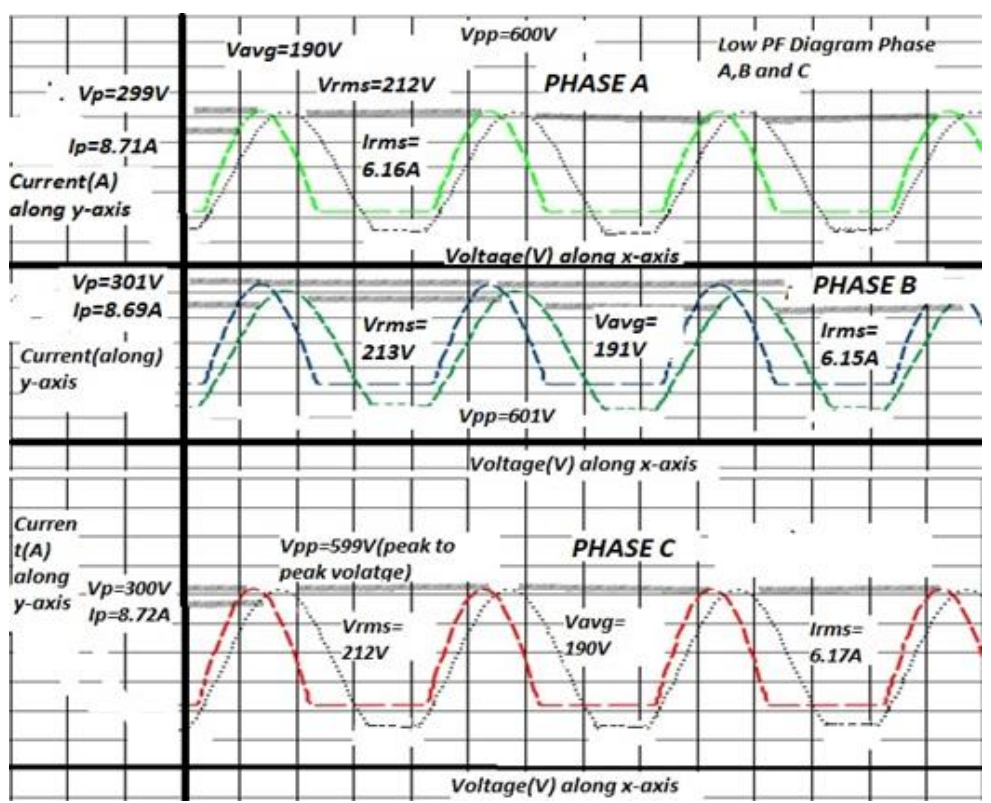

Figure 10. Simulation results (at low pf) when Phase A, B and C inductive loads are ON

\subsubsection{Simulation results improved $P F$}

Figure 11 shows the waveform of improve power factor (Phase A, Phase B and Phase C). In Phase A $V_{r m s}=220 V$, Peak Volage is $V_{p}=311 \mathrm{~V}$ and Peak Current is $I_{p}=4.15 \mathrm{~A}$ and average voltage is $V_{\text {avg }}=198 \mathrm{~V}$ and $R m s$ value of current is $I_{r m s}=2.94 \mathrm{~A}$. In Phase $B V_{r m s}=220 V$, Peak Volage is $V_{p}=311 \mathrm{~V}$ and Peak Current is $I_{p}=4.21 \mathrm{~A}$ and average voltage is $V_{a v g}=197 \mathrm{~V}$ and $R m s$ value of current is $I_{r m s}=2.98 A$.In Phase C

Power factor improvement for a three-phase system using reactive power compensation (Majid Ali) 
$V_{\text {rms }}=220 \mathrm{~V}$, Peak Volage is $V_{p}=311 \mathrm{~V}$ and Peak Current is $I_{p}=4.16 \mathrm{~A}$ and average voltage is $V_{\text {avg }}=197 \mathrm{~V}$ and Rms value of current is $\mathrm{I}_{\mathrm{rms}}=2$.98A.In improve Power Factor, Power losses of the system is reduced and efficiency is increased.

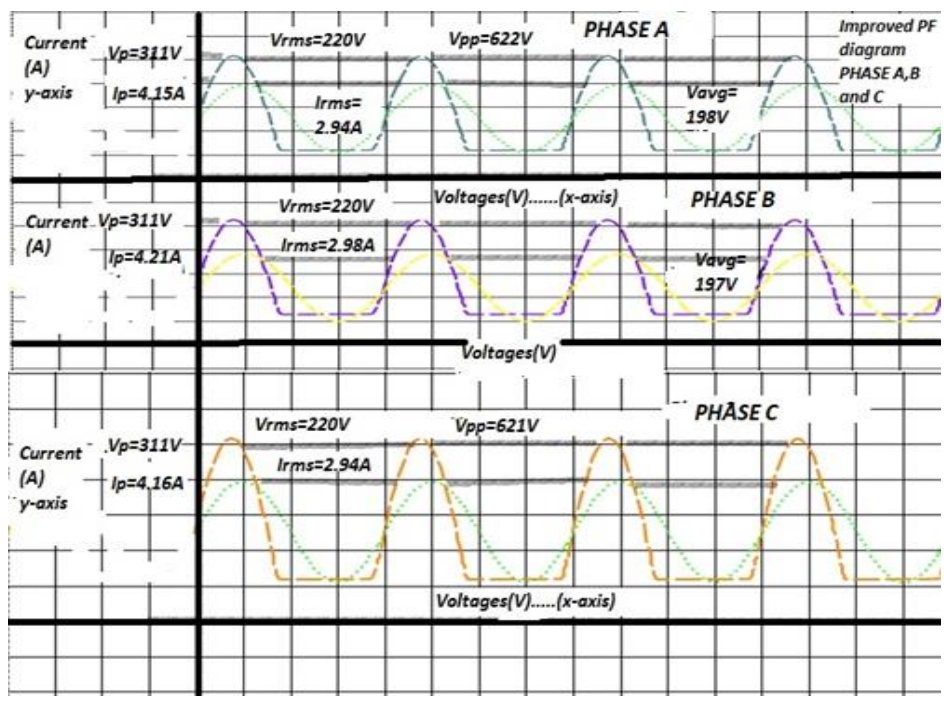

Figure 11. Hardware simulation results (at Improve pf) when Phase A, B and C inductive loads are ON

\subsection{Hardware results}

CT is connected to source in series to measure current PT is connected to source with parallel to measure voltages. Phase Difference or zero crossing can be measure by Voltage divider circuit and current divider circuit. Metal oxide semiconductor field effect transistor (MOSFET) interferon regulatory factor (IRF) $540(\mathrm{~N}$-channel) has been used to amplify the voltage. The Gate signal can apply through Arduino Mega 2560pin (41,42,43(Phase C),45,46,47,48(Phase B),49,50,51(Phase A). Adapter is used to step down the voltage from $240 \mathrm{~V}$ to $12 \mathrm{~V}$ further buck converter convert voltages from $12 \mathrm{~V}$ to $5 \mathrm{~V}$ and it's connected with pin 5 of Arduino. There are 15 capacitors are used for each phase and in total 45 capacitors are used for three Phase A, B and C. Design of Hardware is given in Figure 12.

\subsubsection{Hardware calculation}

Hardware results are shown in Table 3. When all three phases inductive loads are on, the number of capacitors is on 40 automatically and its binary number is (101000). At no load power factor is 0.67 and with load power factor is 0.93 (targeted value of power factor) to improve the efficiency of three phase system. The load use in design is $41.82 \mathrm{KW}$.

\subsubsection{Hardware}

LCD display results $20 \times 4$. LCD $20 \times 4$ displays the results of low value of power factor $(0.67)$ and improved value of power factor (0.93). Switching of capacitor is done automatically and hence we improve the power factor. Low and improve power factor are shown in Figure 13.

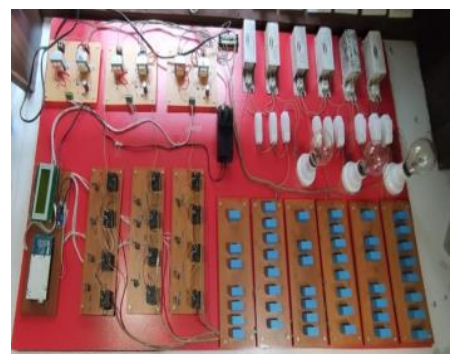

Figure 12. Hardware implementation of the system
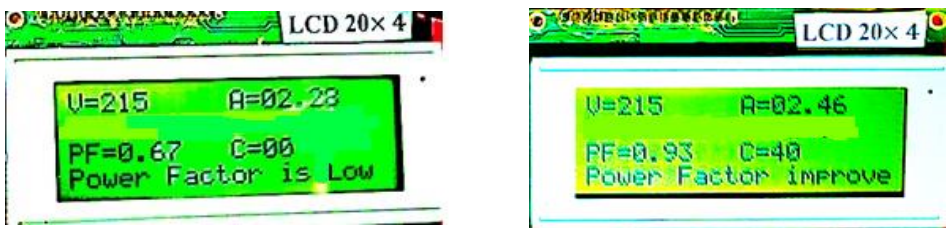

Figure 13. Hardware LCD display results at low power factor and improved power factor 
Table 3. Hardware calculation results

\begin{tabular}{cccccc}
\hline & Current (A) & Reactive Power (KVAR) & Apparent Power (KVA) & Capacitor ON & PF \\
\hline $215 \mathrm{~V}$ & $2.28 \mathrm{~A}$ & $46.32 \mathrm{VAR}$ & $62.41 \mathrm{KVA}$ & 00 & 0.67 \\
$215 \mathrm{~V}$ & $2.46 \mathrm{~A}$ & $16.50 \mathrm{VAR}$ & $44.96 \mathrm{KVA}$ & 40 & 0.93 \\
\hline
\end{tabular}

\subsubsection{Hardware results low power factor}

In Phase $A V_{r m s}=219 V$, Peak Volage is $V_{p}=309 \mathrm{~V}$ and Peak Current is $I_{p=} 3.25 \mathrm{~A}$ and Rms value of current is $I_{r m s}=2.30 A$. In Phase $B V_{r m s}=219 \mathrm{~V}$, Peak Volage is $V_{p}=311 V$ and Peak Current is $I_{p=} 1.69 A$ and $R m s$ value of current is $I_{r m s}=1.20 A$. In Phase $C V_{r m s}=219 V$, Peak Volage is $V_{p}=311 V$ and Peak Current is $I_{p=1} 1.64 A$ and Rms value of current is $I_{r m s}=1.16$ A. Figure 14 show low PF waveform.

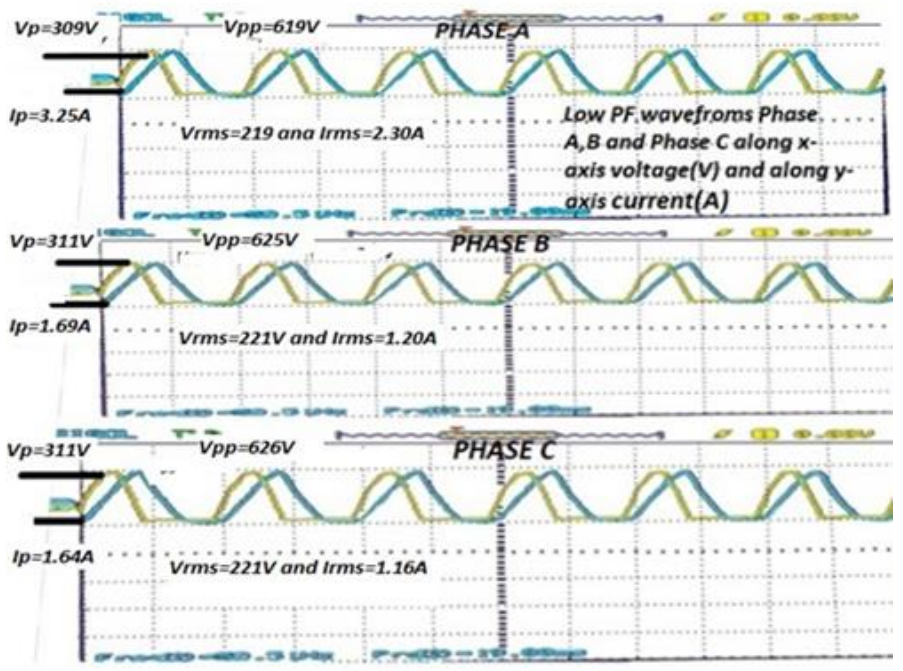

Figure 14. Hardware simulation results (at low pf) when Phase A, B and C inductive loads are ON

\subsubsection{Hardware results improve power factor}

Figure 15 shows the waveform of improve power factor (Phase A, Phase B and Phase C). In Phase A $V_{r m s}=221 \mathrm{~V}$, Peak Volage is $V_{p}=312 \mathrm{~V}$ and Peak Current is $I_{p=1.65 A}$ and Rms value of current is $I_{r m s}=$

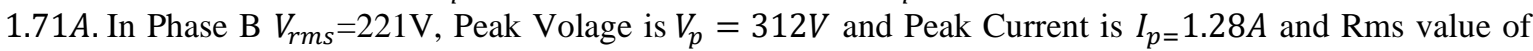
current is $I_{r m s}=0.91 A$.In Phase $\mathrm{C} \mathrm{V}_{\mathrm{rms}}=221 \mathrm{~V}$, Peak Volage is $V_{p}=312 \mathrm{~V}$ and Peak Current is $\mathrm{I}_{\mathrm{p}=1.01 \mathrm{~A}}$ and Rms value of current is $\mathrm{I}_{\mathrm{rms}}=0.72 \mathrm{~A}$

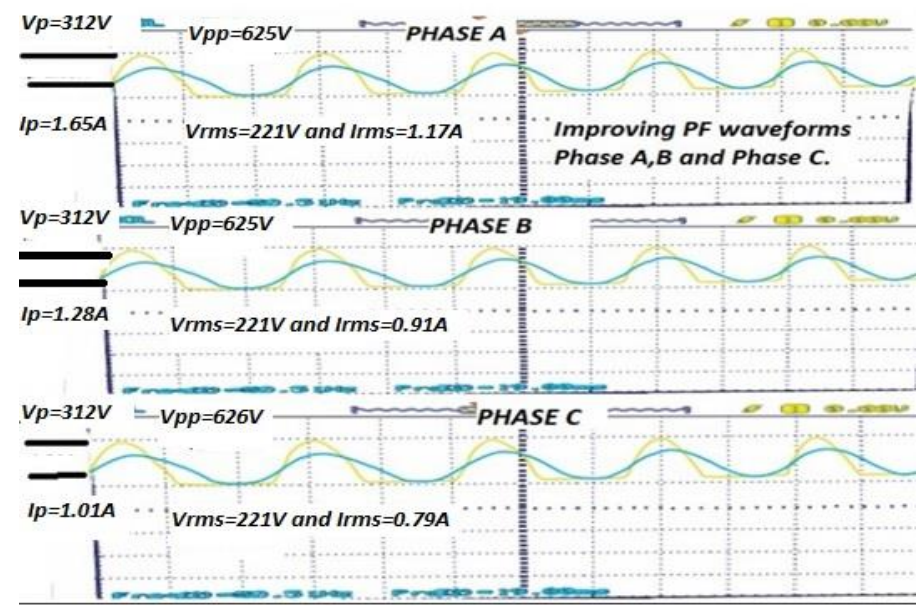

Figure 15. Hardware simulation results (at improve pf) when Phase A, B and C inductive loads are ON

Power factor improvement for a three-phase system using reactive power compensation (Majid Ali) 


\section{CONCLUSION}

Power factor correction scheme is designed primarily depend upon microcontroller and capacitors banks which are utilized for the estimation and checking of modeled electrical stack. In this paper the power factor has been improved by using the capacitors banks and by using microcontroller for Three phase systems. Before the system automatic power factor correction utilizing reactive power compensation for three phase systems the conclusion was per year payment before corrected is $12.59 \$$ and per year payment after power factor corrected is $9.27 \$$ and annual savings is $3 \$$. After the design of systems, the conclusion was per year payment before corrected is $13.12 \$$ and per year payment after power factor corrected is $9.12 \$$ and annual savings is $4 \$$. The annual savings is to increase in the design, so Automatic Power Factor Correction utilizing Reactive Power Compensation is better than the previous design.

\section{ACKNOWLEDGEMENTS}

Authors would to thanks the King Abdulaziz University, KSA for providing the financial resources for the completion of this work.

\section{REFERENCES}

[1] A. J. Hanson and D. J. Perreault, "A high-frequency power factor correction stage with low output voltage," $J$. Emerg. Sel. Top. Power Electron., vol. 8, no. 3, pp. 2143-2155, 2019, doi: 10.1109/JESTPE.2019.2961853.

[2] V. M. L. Martin, F. J. Azcondo, and A. Pigazo, "Power quality enhancement in residential smart grids through power factor correction stages," IEEE Trans. Ind. Electron., vol. 65, no. 11, pp. 8553-8564, 2018, doi: 10.1109/TIE.2018.2813965.

[3] F. Zheng and W. Zhang, "Long term effect of power factor correction on the industrial load: A case study," in 2017 Australasian Universities Power Engineering Conference (AUPEC), 2017, pp. 1-5, doi: 10.1109/AUPEC.2017.8282382.

[4] J. Ye, H. B. Gooi, B. Wang, Y. Li, and Y. Liu, "Elliptical restoration based single-phase dynamic voltage restorer for source power factor correction," Electr. Power Syst. Res., vol. 166, pp. 199-209, 2019, doi: 10.1016/j.epsr.2018.10.011.

[5] S. Setiyono and B. Dwinanto, "Single Phase Power Factor Improvement Based Instantaneous Power PQ Theorm," Bull. Comput. Sci. Electr. Eng., vol. 1, no. 2, pp. 42-53, 2020, doi: 10.25008/bcsee.v1i2.9.

[6] M. U. Hashmi, D. Deka, A. Bušić, L. Pereira, and S. Backhaus, "Arbitrage with power factor correction using energy storage," IEEE Trans. Power Syst., vol. 35, no. 4, pp. 2693-2703, 2020, doi: 10.1109/TPWRS.2020.2969978.

[7] A. Taye, "Design and Simulation of Automatic Power Factor Correction for Industry Application," Int. J. Eng. Technol. Manag. Res., vol. 5, no. 2, pp. 10-21, 2018, doi: 10.29121/ijetmr.v5.i2.2018.142.

[8] T. W. Ngwe, S. Winn, and S. M. Myint, "Design and Control of Automatic Power Factor Correction (APFC) for Power Factor Improvement in Oakshippin Primary Substation," Int. J. Trend Sci. Res. Dev. IJTSRD, vol. 2, no. 5, pp. 2368-2373, 2018, doi: 10.31142/ijtsrd18320.

[9] R. Dhameliya, K. Domadiya, P. Miyani, H. Savaliya, and P. Jariwala, "Automatic power factor control using arduino uno', Int. J. Adv. Eng. Res. Dev. IJAERD, vol. 4, no. 4, 2017, doi: 10.21090/ijaerd.88459.

[10] P. P. Machado, T. P. Abud, M. Z. Fortes, and B. Borba, "Power factor metering system using Arduino," in 2017 IEEE Workshop on Power Electronics and Power Quality Applications (PEPQA), 2017, pp. 1-6. doi: 10.1109/PEPQA.2017.7981633.

[11] A. Anand and B. Singh, "Power factor correction in Cuk-SEPIC-based dual-output-converter-fed SRM drive," IEEE Trans. Ind. Electron., vol. 65, no. 2, pp. 1117-1127, 2017, doi: 10.1109/TIE.2017.2733482.

[12] B. M. Rija, M. K. Hussain, and A. M. Vural, "Microcontroller Based Automatic Power Factor Correction for Single-Phase Lagging and Leading Loads," Eng. Technol. Appl. Sci. Res., vol. 10, no. 6, pp. 6515-6520, 2020, doi: 10.48084 /etasr.3916.

[13] A. H. Nebey, "Automatic load sharing of distribution transformer for overload protection," BMC Res. Notes, vol. 13, no. 1, pp. 1-6, 2020, doi: 10.1186/s13104-019-4880-1.

[14] F. Rashid, R. Ahmad, H. M. Talha, and A. Khalid, "Dynamic Load Sharing at Domestic Level Using the Internet of Things," Int. J. Integr. Eng., vol. 12, no. 4, pp. 57-65, 2020, doi: 10.30880/ijie.2020.12.04.006.

[15] R. Goswami, S. Wang, E. Solodovnik, and K. J. Karimi, "Differential mode active EMI filter design for a boost power factor correction AC/DC converter," IEEE J. Emerg. Sel. Top. Power Electron., vol. 7, no. 1, pp. 576-590, 2018, doi: 10.1109/JESTPE.2018.2839734.

[16] I. J. Smith and J. Salmon, "High-efficiency operation of an open-ended winding induction motor using constant power factor control," IEEE Trans. Power Electron., vol. 33, no. 12, pp. 10663-10672, 2018, doi: 10.1109/TPEL.2018.2806740.

[17] S. R. Islam, S. Maxwell, M. K. Hossain, S.-Y. Park, and S. Park, "Reactive power distribution strategy using power factor correction converters for smart home application," in 2016 IEEE Energy Conversion Congress and Exposition (ECCE), 2016, pp. 1-6, doi: 10.1109/ECCE.2016.7855377. 
[18] M. R. Miranda, D. F. S. Flórez, J. R. C. Chan, E. E. O. López, M. F. Bañuelos, and D. P. Catalán, "The control scheme of the multifunction inverter for power factor improvement," Energies, vol. 11, no. 7, p. 1662, 2018, doi: 10.3390/en11071662.

[19] H. Z. Azazi, S. M. Ahmed, and A. E. Lashine, "Single-stage three-phase boost power factor correction circuit for AC-DC converter," Int. J. Electron., vol. 105, no. 1, pp. 30-41, 2018, doi: 10.1080/00207217.2017.1335800.

[20] F. Rashid, W. Nadeem, A. Hafeez, and A. Nawaz, "An Effort towards Zero Percent Load Shedding utilizing Four Different Sources," Indian J. Sci. Technol., vol. 12, 2019, doi: 10.17485/ijst/2019/v12i28/146229.

[21] M. E. E. Alahi, L. Xie, S. Mukhopadhyay, and L. Burkitt, "A temperature compensated smart nitrate-sensor for agricultural industry," IEEE Trans. Ind. Electron., vol. 64, no. 9, pp. 7333-7341, 2017, doi: 10.1109/TIE.2017.2696508

[22] P. Prabhu and V. Urundady, "One-cycle controlled bridgeless SEPIC with coupled inductors for PAM control-based BLDC drive," Arab. J. Sci. Eng., vol. 44, no. 8, pp. 6987-7001, 2019, doi: 10.1007/s13369-01903740-x.

[23] S. Mondal and M. Chattopadhyay, "Comparative study of three different bridge-less converters for reduction of harmonic distortion in brushless DC motor," Indones. J. Electr. Eng. Comput. Sci., vol. 20, no. 3, pp. 1185-1193, 2020, doi: 10.11591/ijeecs.v20.i3.pp1185-1193.

[24] V. M. Lopez-Martin, F. J. Azcondo, and A. Pigazo, "Power quality enhancement in residential smart grids through power factor correction stages," IEEE Trans. Ind. Electron., vol. 65, no. 11, pp. 8553-8564, 2018, doi: 10.1109/TIE.2018.2813965.

[25] P. Sen, K. P. Panda, and S. Rout, "A low-cost microcontroller-based prototype design for power factor improvement in transmission line using thyristor switched capacitor scheme," in 2018 Technologies for Smart-City Energy Security and Power (ICSESP), 2018, pp. 1-5, doi: 10.1109/ICSESP.2018.8376687.

\section{BIOGRAHPIES OF AUTHORS}
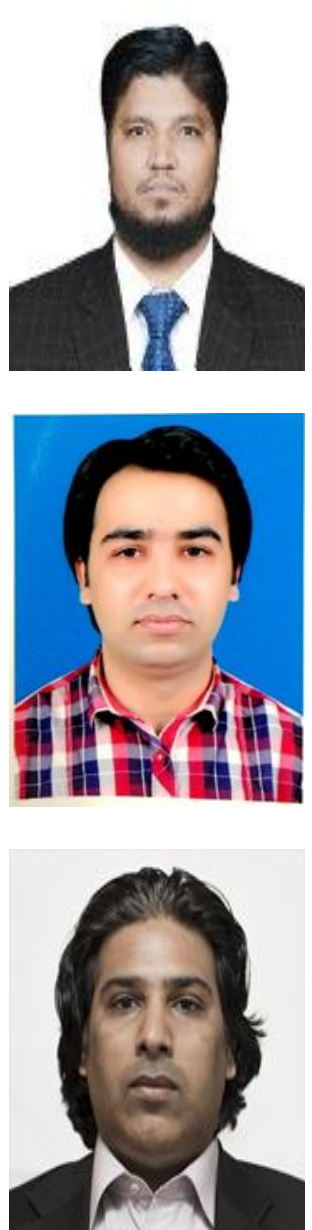

Engr. Majid Ali received his BS (2013) and MS (2015) in Electrical Engineering from University of Management \& Technology (UMT) Lahore Pakistan on fully funded Scholarship. He was Gold and Bronze Medalist in the field of Electrical Technology from Punjab Board of Technical Education (PBTE) Lahore. He joined University of Engineering and Technology (UET) Lahore affiliated college Sharif College of Engineering \& Technology (SCET) in 2013 where he worked till 2016 as Lecturer in the Department of Electrical Engineering. Currently he is working as a Lecturer in Electrical Engineering Department of The University of Lahore His research interest includes Power Distribution Systems, Power system Analysis.

Faizan Rashid was born in Lahore, Pakistan, He received his Bachelor and Master's Degree in Electrical Engineering from The University of Lahore, Pakistan in 2011 and 2017 respectively. He is currently working as a Lecturer in the same university in the Electrical Engineering department. His research interest includes Multilevel Inverters, Distribution systems, Renewable energy resources, Circuit designing, and Machine design. He has also worked on MIMO systems and internet of things. Currently, he is doing work on integration of renewable resources such as Wind and Solar. His interests also include power electronics and its applications in smart grids, ac and dc microgrids, and integration of distribution generation with smart grids.

Dr. Saim Rasheed received a B.Sc. with majors in Mathematics and Physics from Forman Christian College (FCC Lahore, Pakistan) in 1997, he joined COMSATS Institute of Information Technology Lahore for MS in Computer Science. He then completed his $\mathrm{PhD}$ in Computer Science in 2011 from University of Milan (Milan, Italy). Currently he is working as an Assistant Prof in King Abdul Aziz University at Department of Information Technology. His research interests include Brain-Computer Interfaces, EEG Signal Processing, Digital Image Processing, Computer Graphics, Computer Vision and Human-Computer Interaction and Interaction Design. 